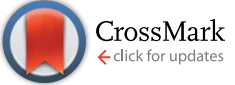

Cite this: RSC Adv., 2017, 7, 13911

\title{
Influence of Cu doping on the visible-light-induced photocatalytic activity of $\mathrm{InVO}_{4} \dagger$
}

\author{
Natda Wetchakun, ${ }^{* a}$ Pimonrat Wanwaen, ${ }^{a}$ Sukon Phanichphant ${ }^{\mathrm{b}}$ \\ and Khatcharin Wetchakun ${ }^{c}$
}

The photocatalytic degradation of methylene blue (MB) in the presence of pure $\operatorname{lnVO}_{4}$ or a $0.5-5.0 \mathrm{~mol} \%$ $\mathrm{Cu}$-doped $\mathrm{InVO}_{4}$ composite under visible light irradiation $(\lambda \geq 400 \mathrm{~nm}$ ) was studied in this research. The structural and photophysical properties of the as-prepared samples in the photocatalytic degradation process were investigated. The doping of $\mathrm{InVO}_{4}$ with a $\mathrm{Cu}$ photocatalyst results in wide absorption in the visible-light region and superior visible-light-driven photocatalytic activities in the degradation of $\mathrm{MB}$. The results indicate that the $\mathrm{InVO}_{4}$ sample doped with $1.0 \mathrm{~mol} \%$ of $\mathrm{Cu}$ shows the highest photocatalytic activity. The enhanced photocatalytic activity was attributed to the copper ions acting as trapping sites, facilitating the separation of charge carriers. The main active species for the degradation of MB were investigated to explain the enhancement of the photocatalytic performance of $\mathrm{Cu}$-doped $\operatorname{lnVO}_{4}$. A possible photocatalytic degradation pathway for aqueous MB dye and a charge transfer mechanism for Cu-doped $\mathrm{InVO}_{4}$ were proposed.

Received 22nd November 2016 Accepted 22nd February 2017

DOI: 10.1039/c6ra27138c

rsc.li/rsc-advances gap and a high electron and hole pair recombination rate, resulting in decreased photocatalytic activity. To achieve a high photocatalytic performance, indium vanadate has been modified by various methods, such as metal ion doping ${ }^{16,17}$ and the formation of composites. ${ }^{\mathbf{1 8 - 2 1}}$ The doping strategy is a feasible method for separating the charge carriers of a semiconductor. It can be achieved by introducing impurity atoms into the materials. The aim of doping impurities into $\mathrm{InVO}_{4}$ is to modify the physicochemical properties of the material, which depend upon the type of impurity doping (shallow or deep) and the nature of the valence of the impurity (inert lattice mismatching, donor or acceptor). ${ }^{22-24}$ Copper is a transition metal ion and is widely used as a dopant in metal oxide semiconductors because it can extend optical absorption toward longer wavelengths, provide a large surface area for the adsorption of chemical species, and enable efficient separation of photogenerated charge carriers. ${ }^{25}$ Therefore, identifying appropriate dopants and dopant concentrations is crucial to increase the overall performance of a photocatalyst. In previous papers, $\mathrm{InVO}_{4}$ catalysts have been synthesized using a hydrothermal method, ${ }^{\mathbf{1 3 2 6 - 2 9}}$ by electrospinning, ${ }^{10}$ using a microwave synthesis method, ${ }^{30}$ and in a mixed aqueous solution. ${ }^{31}$ It was found that the different synthesis conditions provided valuable information for choosing appropriate precursors for In and V. For example, Yao et al. (2009) ${ }^{32}$ studied the effect of the starting composition (molar ratio of $\mathrm{In} / \mathrm{V}$ ), $\mathrm{pH}$ value, soaking time and absence/ presence of a polyvinyl pyrrolidone (PVP) additive on the physicochemical properties of $\mathrm{InVO}_{4}$. In 2012, Song et al. ${ }^{9}$ reported that the orthorhombic structure of $\mathrm{InVO}_{4}$ has a higher photocatalytic performance than monoclinic $\mathrm{InVO}_{4}$ for
${ }^{a}$ Department of Physics and Materials Science, Faculty of Science, Chiang Mai University, Chiang Mai 50200, Thailand.E-mail: natda_we@yahoo.com

${ }^{b}$ Materials Science Research Center, Faculty of Science, Chiang Mai University, Chiang Mai 50200, Thailand

${ }^{c}$ Program of Physics, Faculty of Science, Ubon Ratchathani Rajabhat University, Ubon Ratchathani 34000, Thailand

$\dagger$ Electronic supplementary information (ESI) available. See DOI: $10.1039 / \mathrm{c} 6 \mathrm{ra} 27138 \mathrm{c}$ 
photodegradation of nitrobenzene under visible light irradiation. Moreover, literature reviews show that metal ion-doped $\mathrm{InVO}_{4}$ has improved photocatalytic activity for degrading organic molecules. ${ }^{33,34}$ Yan et al. ${ }^{33}$ reported that a Pt-InVO photocatalyst exhibited excellent visible-light-driven photocatalytic activity for the degradation of ciprofloxacin (CIP), achieving 98.2\% degradation. Surprisingly, only one paper has been published on $\mathrm{Cu}$-doped $\mathrm{InVO}_{4} \cdot{ }^{34}$ It is necessary to study the physical and chemical properties of synthesized photocatalysts, and the influence of doping ions on photocatalytic reactions. In this paper, the effect of copper doping on the physicochemical properties and photocatalytic performance of $\mathrm{InVO}_{4}$ were evaluated. The photocatalytic mechanism of Cudoped $\mathrm{InVO}_{4}$ was proposed. An understanding of $\mathrm{Cu}$-doped $\mathrm{InVO}_{4}$ will aid the development of modified $\mathrm{InVO}_{4}$ that operates efficiently under visible light.

\section{Experimental}

\subsection{Material synthesis}

The starting precursors used to synthesize $\mathrm{Cu}$-doped $\mathrm{InVO}_{4}$ were indium nitrate hydrate $\left(\mathrm{In}\left(\mathrm{NO}_{3}\right)_{3} \cdot x \mathrm{H}_{2} \mathrm{O}\right.$, Sigma-Aldrich, USA, 99.9\%), ammonium metavanadate $\left(\mathrm{NH}_{4} \mathrm{VO}_{3}\right.$, SigmaAldrich, US, 99\%), ammonium hydroxide $\left(\mathrm{NH}_{4} \mathrm{OH}\right.$, SigmaAldrich, US, 30\%), nitric acid ( $\mathrm{HNO}_{3}$, Merck, Germany, 65\%), and copper(II) nitrate trihydrate $\left(\mathrm{Cu}\left(\mathrm{NO}_{3}\right)_{2} \cdot 3 \mathrm{H}_{2} \mathrm{O}\right.$, SigmaAldrich, US, 99\%).

Firstly, indium nitrate hydrate and ammonium metavanadate were dissolved in deionized water and nitric acid, respectively with a molar ratio of $1: 1$. Then, $6.0 \mathrm{M}$ ammonium hydroxide was slowly added to the above solutions to adjust the $\mathrm{pH}$ value to 7 . The mixture solution was treated at a temperature of $200{ }^{\circ} \mathrm{C}$ for $24 \mathrm{~h}$ in a Teflon-lined stainless steel autoclave. Finally, the precipitated $\mathrm{InVO}_{4}$ particles were obtained after washing with deionized water by centrifugation at $7000 \mathrm{rpm}$ for 10 min several times until the $\mathrm{pH}$ was equal to 7 , and drying at $70{ }^{\circ} \mathrm{C}$ in air overnight.

To achieve doping, a calculated nominal copper content of 0.5-5.0 mol\%, from copper(II) nitrate trihydrate as the precursor for copper, was subsequently added to the prepared mixture solution of indium nitrate hydrate and ammonium vanadate. After the mixture was stirred until it was homogeneous, it was placed in a Teflon-lined stainless steel autoclave and heated at $200{ }^{\circ} \mathrm{C}$ for $24 \mathrm{~h}$. The resulting precipitates were obtained as previously described above.

\subsection{Characterization}

The phase compositions of the prepared samples were analyzed using X-ray diffraction (XRD) preformed on a Philips $\mathrm{X}^{\prime}$ Pert MPD with $\mathrm{Cu} K_{\alpha}$ radiation $(\lambda=0.15406 \mathrm{~nm})$. The specific surface area of the samples was obtained using BET surface area measuring apparatus (autosorb-1MP-Quantachrome) at the boiling point of liquid nitrogen. The microstructure and elemental distribution (In, $\mathrm{V}, \mathrm{O}$ and $\mathrm{Cu}$ ) for $1.0 \mathrm{~mol} \% \mathrm{Cu}$-doped $\mathrm{InVO}_{4}$ were investigated using a scanning electron microscope (SEM, JEOL JSM-5910LV, Japan) and energy dispersive spectroscopy analysis (EDS). A transmission electron microscope (TEM, JEOL JEM-2010) was used to observe the morphology and particle size of the prepared photocatalysts. The UV-vis diffuse reflectance spectra of the samples were measured using a UV-visible spectrophotometer (PerkinElmer Lambda 1050) referenced to $\mathrm{MgO}$. The resulting diffuse reflectance spectra were then converted to absorbance spectra using the Kubelka-Munk function; $F\left(R_{\infty}\right)=\left[1-\left(R_{\infty}\right)\right]^{2} / 2 R_{\infty}$, where $F\left(R_{\infty}\right)$ is the so-called remission or Kubelka-Munk function and $R_{\infty}=R_{\text {sample }} / R_{\text {standard }}$. The band gap energy was then obtained from a plot between $1241 / \lambda_{\text {onset }}$ and $\left[F\left(R_{\infty}\right) h v\right]^{1 / 2}$, where $h$ is Planck's constant $\left(6.626 \times 10^{-34} \mathrm{~m}^{2} \mathrm{~kg} \mathrm{~s} \mathrm{~s}^{-1}\right)$, and $v$ is the frequency in $\mathrm{Hz}^{35,36} \mathrm{X}$-ray photoelectron spectroscopy (XPS) was carried out on an AXIS ULTRA ${ }^{\text {DLD }}$, Kratos analytical instrument using nonmonochromatic $\mathrm{Al} \mathrm{K}_{\alpha} \mathrm{X}$-rays at $1.4 \mathrm{keV}$ as the excitation source and choosing $\mathrm{C} 1 \mathrm{~s}(285.6 \mathrm{eV})$ as the reference line. The photoluminescence (PL) spectra of the photocatalysts were recorded using an AvaSpec-2048TEC-USB2-2 spectrophotometer with LEDs (Oceans optics, LLS-345) as an excitation light source.

\subsection{Photodegradation measurements}

The photocatalytic activities of the as-prepared pure $\mathrm{InVO}_{4}$ and 0.5-5.0 mol\% Cu-doped $\mathrm{InVO}_{4}$ samples were evaluated by observing the photodegradation of $\mathrm{MB}$ in aqueous solutions under visible light irradiation $(\lambda \geq 400 \mathrm{~nm})$, using a $50 \mathrm{~W}$ halogen lamp with a glass filter to block UV components. The initial concentration of MB was $2 \times 10^{-5} \mathrm{M}$. In each experiment, $0.1 \mathrm{~g}$ of the photocatalyst was suspended in an aqueous solution $(100 \mathrm{~mL})$ of $\mathrm{MB}$ in a slurry reactor. Prior to irradiation, the suspension was stirred in the dark for $30 \mathrm{~min}$ to ensure the establishment of an adsorption-desorption equilibrium. At given time intervals of $15 \mathrm{~min}, 5 \mathrm{~mL}$ of the suspension was collected and centrifuged at $7000 \mathrm{rpm}$ for $5 \mathrm{~min}$ to remove the catalyst powders. The concentration of MB was then detected by measuring the maximum absorbance at $664 \mathrm{~nm}$ using a spectrophotometer. For the stability test, the remaining photocatalyst powder after photocatalytic degradation of $\mathrm{MB}$ in suspension was collected by centrifugation, washed with deionized water to remove the residual $\mathrm{MB}$, and then dried before being used in another photocatalytic reaction. This process was repeated five times.

\section{Results and discussion}

\subsection{Material characterization}

Fig. 1a shows the XRD patterns of the pure $\mathrm{InVO}_{4}$ and $0.5-5.0$ $\mathrm{mol} \% \mathrm{Cu}$-doped $\mathrm{InVO}_{4}$ samples. The diffraction patterns of all the samples were well matched with the orthorhombic phase (JCPDS file no. 48-0898). No other diffraction peaks were observed in the XRD patterns of the Cu-doped $\mathrm{InVO}_{4}$ samples. This suggests that there is no impurity phase formation, which could occur from chemical reactions between $\mathrm{Cu}$ and $\mathrm{InVO}_{4}$. The diffraction peak at $33.18^{\circ}$ is the main characteristic of the (112) plane of pure $\mathrm{InVO}_{4}$. This peak is slightly shifted towards lower angles with an increasing amount of copper doping, suggesting that $\mathrm{In}^{3+}$ ions $(0.80 \AA)$ are substituted for smaller- 

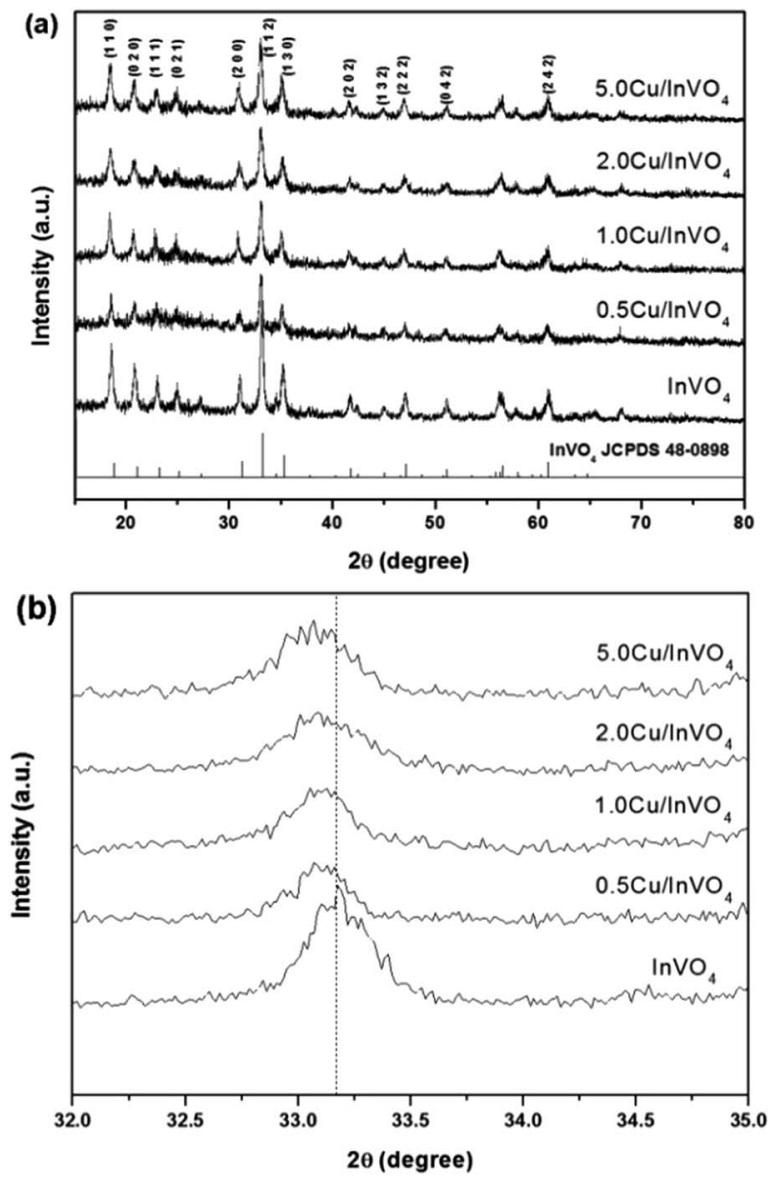

Fig. 1 XRD patterns of pure $\operatorname{InVO}_{4}$ and $\mathrm{Cu}$-doped $\operatorname{InVO}_{4}$ with a nominal copper content of $0.5-5.0 \mathrm{~mol} \%$ in the $2 \theta$ range of (a) $15-$ $80^{\circ}$ and (b) $32-35^{\circ}$

sized $\mathrm{Cu}^{2+}$ ions $(0.73 \AA)$ in $\mathrm{InVO}_{4}$ (Fig. 1b). Moreover, the incorporation of copper ions in the $\mathrm{InVO}_{4}$ lattice caused the expansion of the crystalline planes in the $\mathrm{InVO}_{4}$ crystal structure. The interplanar spacing $\left(d_{h k l}\right)$ values of all the samples were calculated from the (112) plane (the $d_{h k l}$ values of all the samples are given in the ESI, Table S1 $\dagger$ ). The interplanar spacing of the (112) orthorhombic crystallographic plane of the 0.5-5.0 mol\% Cu-doped $\mathrm{InVO}_{4}$ samples increased compared with pure $\mathrm{InVO}_{4}$, implying that $\mathrm{Cu}^{2+}$ ions are substituted into the orthorhombic $\mathrm{InVO}_{4}$ lattice. Therefore, disorder of the crystalline structure of the $\mathrm{InVO}_{4}$ samples was promoted by copper substitution.

The specific surface area of $\mathrm{InVO}_{4}$ was $19.97 \mathrm{~m}^{2} \mathrm{~g}^{-1}$ based on the BET method using $\mathrm{N}_{2}$ adsorption, which was lower than that of $1.0 \mathrm{~mol} \% \mathrm{Cu}$-doped $\mathrm{InVO}_{4}\left(50.50 \mathrm{~m}^{2} \mathrm{~g}^{-1}\right)$. In general, the photocatalytic performance depends on many parameters, such as the surface area, adsorption capacity, optical absorption, carrier recombination rate, etc. ${ }^{37,38}$ A larger surface area in most cases corresponds to a smaller particle size and a higher adsorption capacity, leading to enhanced photocatalytic activity.

A scanning electron microscope (SEM) image of $1.0 \mathrm{~mol} \%$ $\mathrm{Cu}$-doped $\mathrm{InVO}_{4}$ is shown in Fig. 2. The average diameter of the agglomerated particles of $1.0 \mathrm{~mol} \% \mathrm{Cu}$-doped $\mathrm{InVO}_{4}$ is about
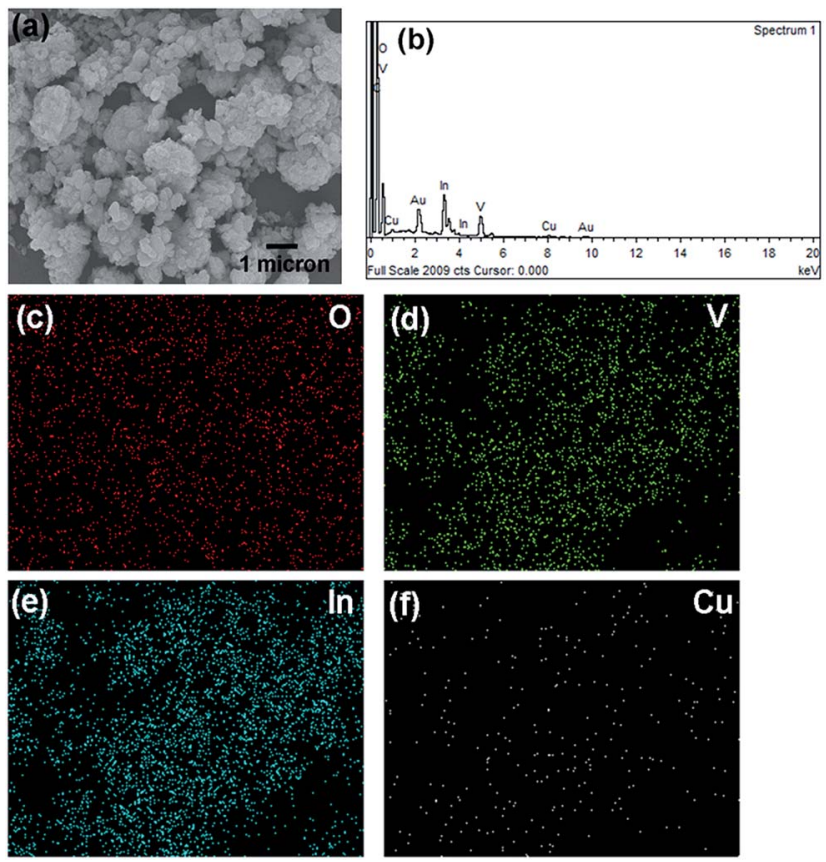

Fig. 2 (a) SEM image, (b) EDS spectrum, and (c-f) elemental mapping of $1.0 \mathrm{~mol} \% \mathrm{Cu}$-doped $\mathrm{InVO}_{4}$.

100-200 nm. The EDS spectrum of $1.0 \mathrm{~mol} \% \mathrm{Cu}$-doped $\mathrm{InVO}_{4}$ revealed that the emission peaks correspond to In, $\mathrm{V}, \mathrm{O}$ and $\mathrm{Cu}$, along with $\mathrm{Au}$ and $\mathrm{C}$ peaks, which might have come from gold sputtering and the carbon tape used to fix the sample on the sample holder, respectively (Fig. 2b). Fig. 2c-f present the elemental mapping of $1.0 \mathrm{~mol} \% \mathrm{Cu}$-doped $\mathrm{InVO}_{4}$, indicating the uniform distribution of $\mathrm{In}, \mathrm{V}, \mathrm{O}$ and $\mathrm{Cu}$ in the $1.0 \mathrm{~mol} \% \mathrm{Cu}-$ doped $\mathrm{InVO}_{4}$ sample.

Fig. 3 shows the TEM images for pure $\mathrm{InVO}_{4}$ and $1.0 \mathrm{~mol} \%$ $\mathrm{Cu}$-doped $\mathrm{InVO}_{4}$ after hydrothermal reaction at $200{ }^{\circ} \mathrm{C}$ for $24 \mathrm{~h}$. In Fig. $3 \mathrm{a}$, the particle diameters for pure $\mathrm{InVO}_{4}$ were measured

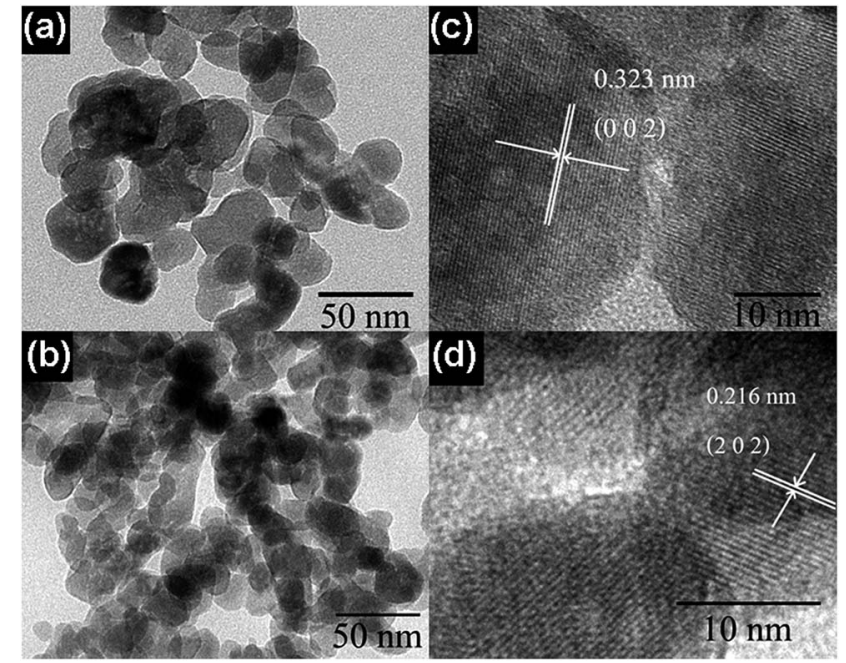

Fig. 3 TEM images and lattice fringes of ( $a$ and $c$ ) pure $\operatorname{lnVO}_{4}$ and (b and d) $1.0 \mathrm{~mol} \% \mathrm{Cu}$-doped $\mathrm{InVO}_{4}$ 
to range from $20 \mathrm{~nm}$ to $30 \mathrm{~nm}$. The characteristics of the 1.0 mol\% Cu-doped $\mathrm{InVO}_{4}$ particles can be observed from Fig. $3 \mathrm{~b}$. The particle diameters were determined to be in the range of $15 \mathrm{~nm}$ to $20 \mathrm{~nm}$, so the particles are significantly smaller than those of pure $\mathrm{InVO}_{4}$. This may be due to the $\mathrm{Cu}$ ions retarding the growth of the crystallites. The lattice fringes of the sphericallike particles of pure $\mathrm{InVO}_{4}$ can be observed in Fig. 3c. The interplanar spacing of $\mathrm{InVO}_{4}$ was found to be $d_{002}=0.323 \mathrm{~nm}$. The lattice fringe of $1.0 \mathrm{~mol} \% \mathrm{Cu}$-doped $\mathrm{InVO}_{4}$ corresponds to the $d$-spacing of $0.216 \mathrm{~nm}$, which is consistent with the spacing of the (202) plane (Fig. 3d).

The diffuse reflectance spectra of pure $\mathrm{InVO}_{4}$ and $1.0 \mathrm{~mol} \%$ $\mathrm{Cu}$-doped $\mathrm{InVO}_{4}$ are shown in Fig. 4. The absorption margin of the $1.0 \mathrm{~mol} \% \mathrm{Cu}$-doped $\mathrm{InVO}_{4}$ sample dramatically shifts to a longer wavelength, indicating a decrease in the band gap with respect to pure $\mathrm{InVO}_{4}$. The absorption spectra of the pure $\mathrm{InVO}_{4}$ and $1.0 \mathrm{~mol} \% \mathrm{Cu}$-doped $\mathrm{InVO}_{4}$ samples indicated maximum absorption at $642 \mathrm{~nm}$ and $600 \mathrm{~nm}$, which corresponded to band gaps of $1.93 \mathrm{eV}$ and $2.07 \mathrm{eV}$, respectively (Fig. $4 \mathrm{a}$ and b). The differences in absorption between pure $\mathrm{InVO}_{4}$ and $1.0 \mathrm{~mol} \%$ $\mathrm{Cu}$-doped $\mathrm{InVO}_{4}$ may be due to the different sizes and types of photocatalyst particles present in the samples leading to
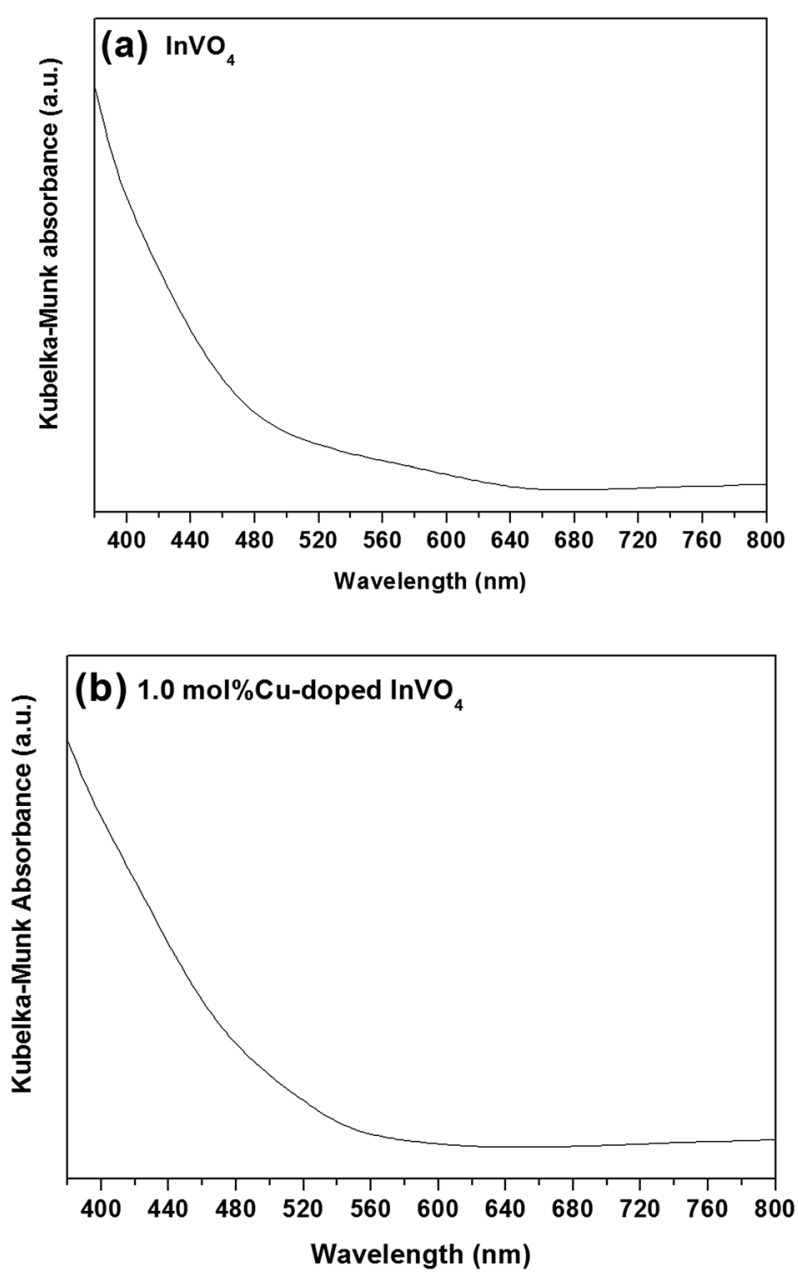

Fig. 4 Kubelka-Munk absorbance spectra of the pure $\operatorname{InVO}_{4}(a)$ and $1.0 \mathrm{~mol} \% \mathrm{Cu}$-doped $\mathrm{InVO}_{4}$ (b) samples. different light scattering and absorption properties. ${ }^{39,40}$ The narrow band gap implies that the photocatalytic performance was enhanced under visible light irradiation, as previously reported. ${ }^{41,42}$

The elemental composition and chemical states of the elements in the samples were analyzed using the XPS technique. Fig. 5a shows the typical In $3 \mathrm{~d}_{5 / 2}$ core level spectrum for $1.0 \mathrm{~mol} \% \mathrm{Cu}$-doped $\mathrm{InVO}_{4}$, with the peaks at binding energy (BE) values of $444.76 \mathrm{eV}$ and $445.79 \mathrm{eV}$ for In $3 \mathrm{~d}_{5 / 2}$ and In $3 \mathrm{~d}_{3 / 2}$, respectively, assigned to $\mathrm{In}^{3+}$ in $\mathrm{InVO}_{4} \cdot{ }^{43,44}$ For the In $3 \mathrm{~d}$ region, the peaks of In $3 \mathrm{~d}_{5 / 2}$ and In $3 \mathrm{~d}_{3 / 2}$ at $452.32 \mathrm{eV}$ and $453.70 \mathrm{eV}$, respectively, corresponded to $\mathrm{In}^{3+}$ species. ${ }^{45}$ The $\mathrm{V} 2 \mathrm{p}$ core level spectrum is shown in Fig. $5 \mathrm{~b}$. The main peaks for $\mathrm{V} 2 \mathrm{p}_{3 / 2}$ and $\mathrm{V}$ $2 \mathrm{p}_{1 / 2}$ were present at $517.23 \mathrm{eV}$ and $524.85 \mathrm{eV}$, respectively, and were attributed to the $\mathrm{V}^{5+}$ oxidation state in $\mathrm{InVO}_{4} \cdot{ }^{46}$ Moreover, the other peaks at about $518.17 \mathrm{eV}$ and $526.27 \mathrm{eV}$ were ascribed to the oxidation state of $\mathrm{V}^{4+} .^{47}$ The reduction of the oxidation state of $\mathrm{V}$ from $\mathrm{V}^{5+}$ to $\mathrm{V}^{4+}$ can be explained by the change of oxygen vacancies in the $\mathrm{InVO}_{4}$ structure during the synthesis of the material. Fig. $5 \mathrm{c}$ shows the $\mathrm{O} 1 \mathrm{~s}$ core level spectrum of 1.0 mol\% Cu-doped $\mathrm{InVO}_{4}$. The $\mathrm{O} 1 \mathrm{~s}$ peak could be fitted by three components at about $530 \mathrm{eV}, 531 \mathrm{eV}$, and $532 \mathrm{eV}$, ascribed to lattice oxygen of the metal oxide semiconductor, adsorbed $\mathrm{OH}$ groups and $\mathrm{H}_{2} \mathrm{O}$, respectively. ${ }^{48,49}$ As shown in the $\mathrm{Cu} 2 \mathrm{p}$ corelevel spectrum (Fig. 5d), the binding energies of $\mathrm{Cu}$ at 932.25 eV and $952.04 \mathrm{eV}$, corresponding to $\mathrm{Cu} 2 \mathrm{p}_{3 / 2}$ and $\mathrm{Cu} 2 \mathrm{p}_{1 /}$ 2, respectively, were attributed to $\mathrm{Cu}^{+} .{ }^{50}$ Moreover, the two characteristic peaks for $\mathrm{Cu} 2 \mathrm{p}$ at $933.95 \mathrm{eV}$ and $954.05 \mathrm{eV}$ corresponding to $\mathrm{Cu} 2 \mathrm{p}_{3 / 2}$ and $\mathrm{Cu} 2 \mathrm{p}_{1 / 2}$, respectively, indicated that copper also existed in the form of $\mathrm{Cu}^{2+} \cdot{ }^{51}$ Therefore, $\mathrm{Cu}^{+}$and $\mathrm{Cu}^{2+}$ species coexisted in $1.0 \mathrm{~mol} \% \mathrm{Cu}$-doped $\mathrm{InVO}_{4}$. The coexistence of $\mathrm{Cu}^{+}$and $\mathrm{Cu}^{2+}$ in $\mathrm{InVO}_{4}$ could be due to the presence of O-deficient $\mathrm{InVO}_{4}$ particles. ${ }^{\mathbf{1 4}}$

\subsection{Photocatalytic performances}

The photodegradation of methylene blue (MB) using $\mathrm{InVO}_{4}$ and 0.5-5.0 mol\% Cu-doped $\mathrm{InVO}_{4}$ nanoparticles under visible light irradiation is illustrated in Fig. 6a. A slight decrease in $\mathrm{MB}$ concentration was observed in the presence of 0.5-5.0 mol\% $\mathrm{Cu}$-doped $\mathrm{InVO}_{4}$. The pure $\mathrm{InVO}_{4}$, and $0.5 \mathrm{~mol} \%, 1.0 \mathrm{~mol} \%, 2.0$ mol\% and 5.0 mol\% Cu-doped $\mathrm{InVO}_{4}$ samples can degrade approximately $8 \%, 30 \%, 37 \%, 61 \%, 51 \%$, and $23 \%$ of $\mathrm{MB}$, respectively under visible light irradiation.

From Fig. $6 a$ and $b$, the photocatalytic activity initially increases with an increasing level of $\mathrm{Cu}$ doping (up to $1.0 \mathrm{~mol} \%$ ) in the $\mathrm{InVO}_{4}$ sample, followed by a decrease in activity with a further increase in the $\mathrm{Cu}$ ion level. The increase in $\mathrm{MB}$ photodegradation with an increase in the amount of $\mathrm{Cu}$ is explained by the ability of the $\mathrm{Cu}$ dopant to act as a charge carrier trap site for electrons. ${ }^{52,53}$ At high $\mathrm{Cu}$ dopant concentrations, the distances between the trapping sites for electrons and holes decrease, resulting in an enhanced recombination rate for electron-hole pairs. Therefore, a high level of $\mathrm{Cu}$ doping increases the concentration of recombination centers, and consequently the photocatalytic efficiency of $\mathrm{InVO}_{4}$ decreases. ${ }^{54,55}$ It is notable that the $1.0 \mathrm{~mol} \% \mathrm{Cu}$-doped $\mathrm{InVO}_{4}$ 

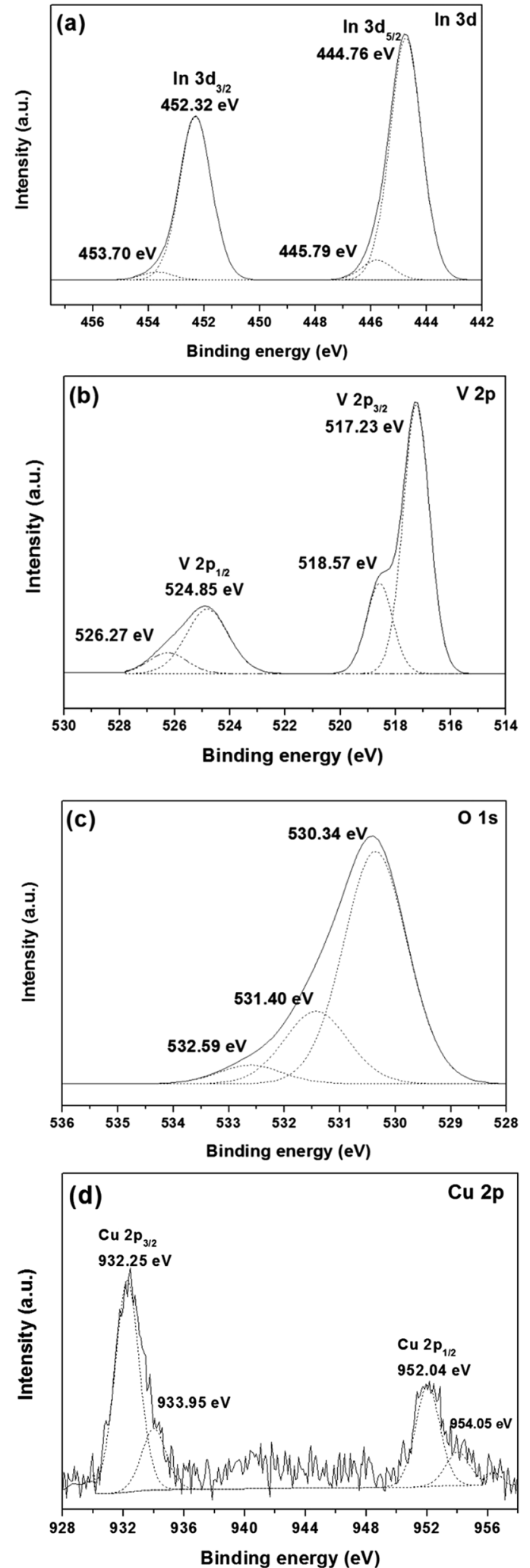

Fig. 5 XPS spectra of (a) In, (b) V, (c) O, and (d) Cu elements for 1.0 mol\% Cu-doped $\mathrm{InVO}_{4}$ samples.

nanoparticles display better degradation properties than the other samples. Thus, the optimal concentration of $\mathrm{Cu}$ doping in $\mathrm{InVO}_{4}$ is favorable for the improvement of the photocatalytic
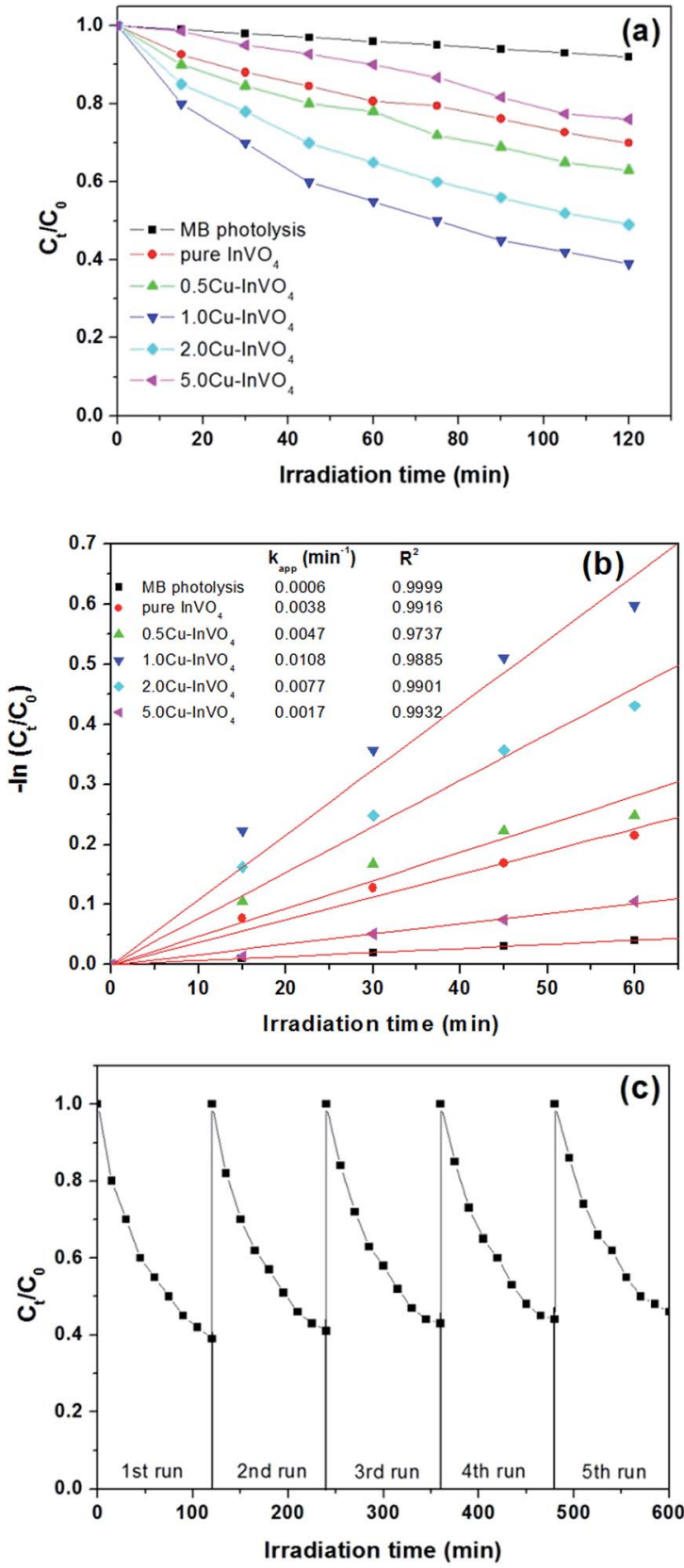

Fig. 6 (a) Photocatalytic degradation of MB as a function of the irradiation time under visible light for all samples; (b) pseudo first order kinetics fitting data for the photodegradation of $\mathrm{MB}$; (c) recyclability of $1.0 \mathrm{~mol} \% \mathrm{Cu}$-doped $\mathrm{InVO}_{4}$ in the degradation of $\mathrm{MB}$ for 5 cycles.

activity in MB degradation. To quantitatively analyze the reaction kinetics of $\mathrm{MB}$ degradation, the experimental data in Fig. $6 \mathrm{~b}$ were fitted using the Langmuir-Hinshelwood model, as expressed by the following equation: ${ }^{56}-\mathrm{d} C / \mathrm{d} t=k_{\text {app }} t$, where $C$ is the concentration of $\mathrm{MB}$ and $k_{\mathrm{app}}$ is the apparent reaction rate constant. Integration of the above equation will give the concentration as a function of time: $:^{57}-\ln \left(C_{t} / C_{0}\right)=k_{\text {app }} t$. From this kinetics analysis, it is evident that the photocatalytic degradation of MB follows pseudo-first order kinetics (Fig. 6b). From the linear fitting curves of $-\ln \left(C_{t} / C_{0}\right)$ versus irradiation time $(t)$, the MB degradation rate constant $\left(k_{\mathrm{app}}\right)$ was calculated 
to be $6.0 \times 10^{-4}, 3.8 \times 10^{-3}, 4.7 \times 10^{-3}, 10.8 \times 10^{-3}, 7.7 \times$ $10^{-3}$, and $1.7 \times 10^{-3}, \min ^{-1}$ for MB photolysis, and photodegradation with pure $\mathrm{InVO}_{4}$, and $0.5 \mathrm{~mol} \%, 1.0 \mathrm{~mol} \%, 2.0$ mol\%, and $5.0 \mathrm{~mol} \% \mathrm{Cu}$-doped $\mathrm{InVO}_{4}$, respectively. Among the different samples, the $1.0 \mathrm{~mol} \% \mathrm{Cu}$-doped $\mathrm{InVO}_{4}$ sample exhibited the highest $k_{\text {app }}$ value. This $\mathrm{Cu}$-doped $\mathrm{InVO}_{4}$ photocatalyst had significantly enhanced photocatalytic activity compared to the pure $\mathrm{InVO}_{4}$ photocatalyst. To evaluate the stability and reusability of the $\mathrm{Cu}$-doped $\mathrm{InVO}_{4}$ photocatalysts, the $1.0 \mathrm{~mol} \% \mathrm{Cu}$-doped $\mathrm{InVO}_{4}$ photocatalyst was recycled for 5 runs of photodegradation of $\mathrm{MB}$, as depicted in Fig. $6 \mathrm{c}$. After 5 successive runs with each reaction lasting for $600 \mathrm{~min}$, the degradation efficiency of the $1.0 \mathrm{~mol} \% \mathrm{Cu}$-doped $\mathrm{InVO}_{4}$ photocatalyst was largely maintained, indicating good stability.

To understand the charge transfer behavior between $\mathrm{CeO}_{2}$ and $\mathrm{InVO}_{4}$, the band edge positions of the conduction band (CB) and the valence band (VB) of $\mathrm{InVO}_{4}$ were calculated using the following equation: $E_{\mathrm{CB}}^{0}=\chi-E^{\mathrm{C}}-0.5 E_{\mathrm{g}},{ }^{58}$ where $\chi$ is the electronegativity of the semiconductor, $E^{\mathrm{C}}$ is the energy of free electrons on the hydrogen scale of $4.5 \mathrm{eV}, E_{\mathrm{g}}$ is the band gap of $\mathrm{InVO}_{4}$, and the $\chi$ value of $\mathrm{InVO}_{4}$ is $5.03 \mathrm{eV}{ }^{59}$ The valence band energy $\left(E_{\mathrm{VB}}\right)$ can be calculated using the following equation: ${ }^{60}$ $E_{\mathrm{VB}}=E_{\mathrm{CB}}+E_{\mathrm{g}}$, where $E_{\mathrm{CB}}$ is the conduction band energy. The $E_{\mathrm{g}}$ value of $\mathrm{InVO}_{4}$ was evaluated from the UV-vis DRS analysis to be about $1.94 \mathrm{eV}$. Based on the equation above, the CB and VB edge potentials of $\mathrm{InVO}_{4}$ were calculated to be -0.44 and $1.50 \mathrm{eV}$, respectively. We further analyzed the photocatalytic mechanism focusing on $\mathrm{Cu}$-doped $\mathrm{InVO}_{4}$ for $\mathrm{MB}$ degradation (Fig. 7). When absorbing visible light with photon energy $(h v)$ equal to or exceeding the band gap, the $\mathrm{Cu}$-doped $\mathrm{InVO}_{4}$ generates electron-hole $\left(\mathrm{e}^{-} / \mathrm{h}^{+}\right)$pairs at the surface, as shown in (eqn (1)).

$$
\text { Cu-doped } \mathrm{InVO}_{4}+h v \rightarrow \mathrm{Cu} \text {-doped } \mathrm{InVO}_{4}\left(\mathrm{~h}_{\mathrm{VB}}{ }^{+}+\mathrm{e}_{\mathrm{CB}}{ }^{-}\right)
$$

The photogenerated holes $\left(\mathrm{h}_{\mathrm{VB}}{ }^{+}\right)$on the surface of $\mathrm{Cu}$-doped $\mathrm{InVO}_{4}$ can react with adsorbed water $\left(\mathrm{H}_{2} \mathrm{O}\right)$ and hydroxide ions

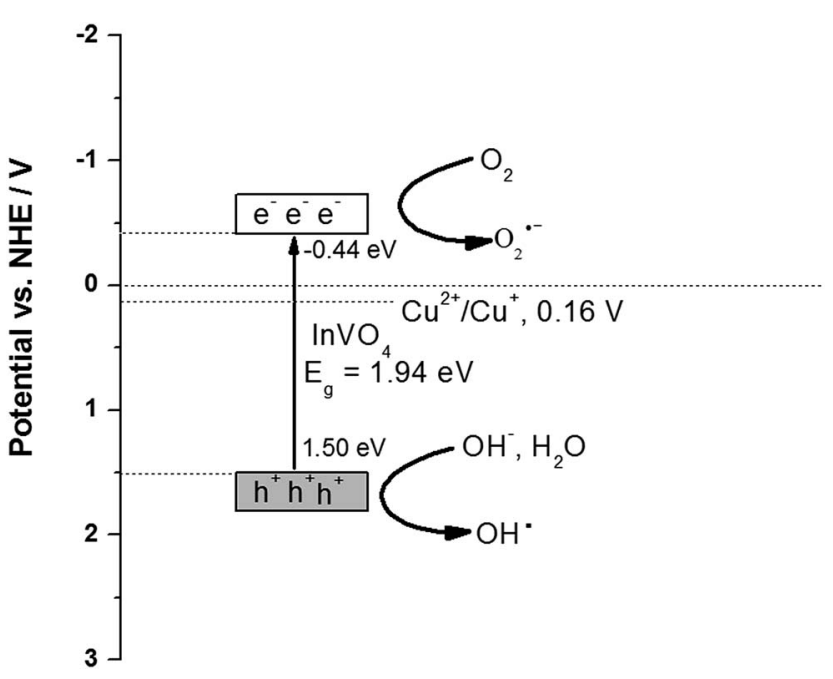

Fig. 7 Schematic of the charge migration and separation on $\mathrm{Cu}$ doped InVO . $^{2}$
$\left(\mathrm{OH}^{-}\right)$to produce hydroxyl radicals $\left(\mathrm{OH}^{*}\right)$ (eqn (2) and (3)). At the same time, $\mathrm{O}_{2}$ acts as an electron acceptor to generate a superoxide anion radical $\left(\mathrm{O}_{2}{ }^{-}\right)$(eqn (4)). The $\mathrm{O}_{2}{ }^{-}$radicals then react with hydroperoxyl radicals $\left(\mathrm{HO}_{2}{ }^{\circ}\right)$ to produce hydrogen peroxide $\left(\mathrm{H}_{2} \mathrm{O}_{2}\right)$, subsequently producing hydroxyl radicals (eqn (5) and (6)).

$$
\begin{gathered}
\text { Cu-doped } \mathrm{InVO}_{4}\left(\mathrm{~h}_{\mathrm{VB}}{ }^{+}\right)+\mathrm{H}_{2} \mathrm{O} \rightarrow \mathrm{OH}^{\cdot}+\mathrm{H}^{+} \\
\text {Cu-doped } \mathrm{InVO}_{4}\left(\mathrm{~h}_{\mathrm{VB}}{ }^{+}\right)+\mathrm{OH}^{-} \rightarrow \mathrm{OH}^{\cdot} \\
\text { Cu-doped } \mathrm{InVO}_{4}\left(\mathrm{e}_{\mathrm{CB}}{ }^{-}\right)+\mathrm{O}_{2} \rightarrow \mathrm{O}_{2}^{\cdot-} \\
\mathrm{O}_{2}^{\cdot-}+\mathrm{HO}_{2}^{\cdot}+\mathrm{H}^{+} \rightarrow \mathrm{H}_{2} \mathrm{O}_{2}+\mathrm{O}_{2} \\
\mathrm{H}_{2} \mathrm{O}_{2} \rightarrow 2 \mathrm{OH}^{\cdot}
\end{gathered}
$$

The hydroxyl radical is a strong reactive species which can degrade methylene blue through the reaction shown in eqn (7).

$$
\mathrm{OH}^{\bullet}+\mathrm{MB} \rightarrow \text { intermediates } \rightarrow \text { degradation products }
$$

Moreover, the photogenerated electron-hole pairs can be separated in surface trap states in Cu-doped $\mathrm{InVO}_{4}$. From the XPS results, the $\mathrm{Cu}^{2+} / \mathrm{Cu}^{+}$ions may act as trapping sites. The $\mathrm{Cu}^{2+}$ ions would easily uptake one photogenerated electron from the $\mathrm{InVO}_{4}$ conduction band. As a result, $\mathrm{Cu}^{2+}$ is quickly reduced to $\mathrm{Cu}^{+}\left(\mathrm{Cu}^{2+} / \mathrm{Cu}^{+}\right.$redox potential $=0.16 \mathrm{~V}$ versus NHE). ${ }^{61} \mathrm{Cu}^{+}$ions might not be stable in the photocatalysis process. Reoxidation would occur by hole trapping and $\mathrm{Cu}^{2+}$ could be formed. $\mathrm{Cu}^{2+} / \mathrm{Cu}^{+}$ion doping can facilitate efficient charge separation, increase the lifetime of electron-hole separation and support charge carrier transfer to the catalyst surface.

Photoluminescence (PL) spectroscopy is widely used to explore the efficiency of transferring charge carriers in semiconductors, which can reflect the separation and recombination of photogenerated electron-hole pairs. Generally, lower PL signals suggest a slower charge carrier recombination rate and

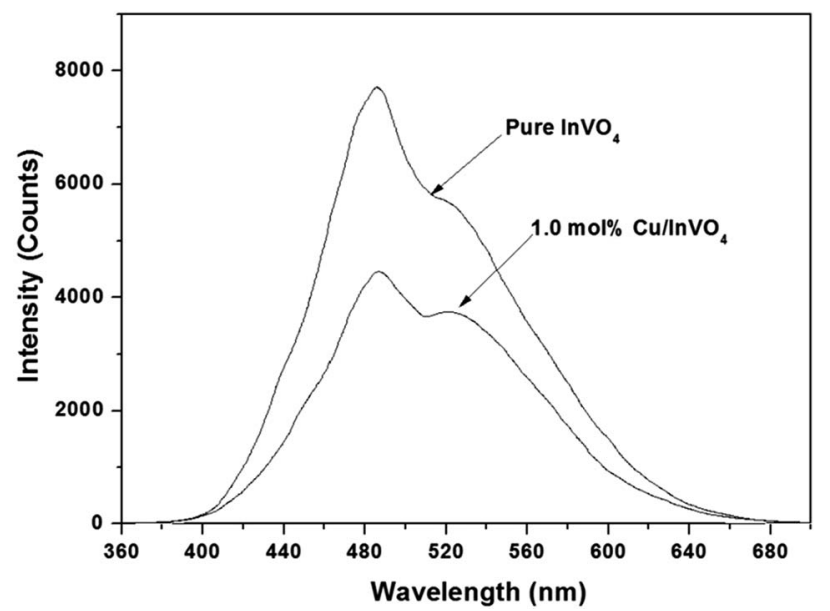

Fig. $8 \mathrm{PL}$ spectra of pure $\operatorname{lnVO}_{4}$ and $1.0 \mathrm{~mol} \% \mathrm{Cu}$-doped $\mathrm{InVO}_{4}$ samples. 


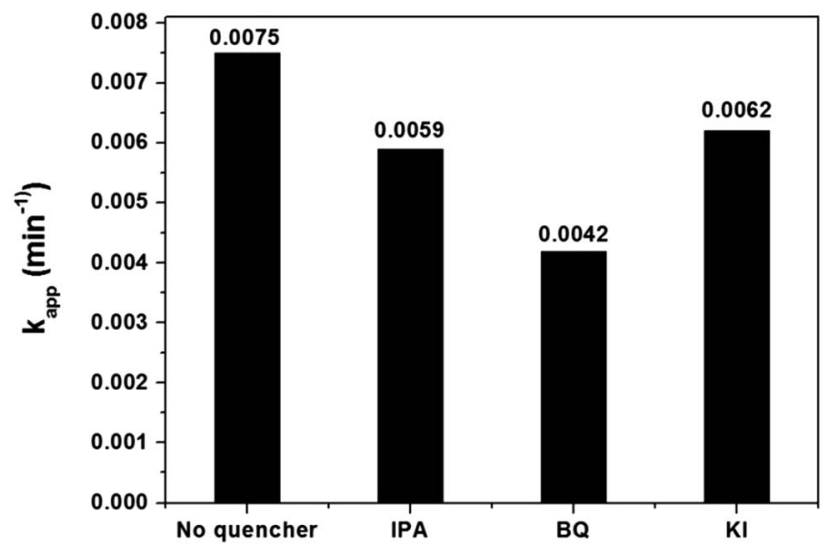

Fig. 9 Effect of different scavengers on the photocatalytic degradation of $\mathrm{MB}$ over $1.0 \mathrm{~mol} \% \mathrm{Cu}$-doped $\mathrm{InVO}_{4}$ under visible light irradiation.

a higher separation efficiency. As shown in Fig. 8, the PL spectrum of $1.0 \mathrm{~mol} \% \mathrm{Cu}$-doped $\mathrm{InVO}_{4}$ displayed the lowest PL intensity. In contrast, pure $\mathrm{InVO}_{4}$ had a relatively higher PL intensity. This result implies that the recombination rate of photogenerated electron-hole pairs was inhibited after doping with copper.

The reactive species, such as $\mathrm{h}^{+}, \mathrm{OH}^{\cdot}$ and $\mathrm{O}_{2}{ }^{\cdot-}$, significantly influence the photocatalytic performance by degrading organic compounds. To clarify the photocatalytic mechanism, the main reactive species were investigated using trapping experiments for MB degradation over $1.0 \mathrm{~mol} \% \mathrm{Cu}$-doped $\mathrm{InVO}_{4}$. Different quenchers were added in the photocatalytic degradation of $\mathrm{MB}$ under visible light irradiation. In this case, isopropanol ( $2 \mathrm{mM})$, benzoquinone (BQ, $2 \mathrm{mM})$, and potassium iodide $(2 \mathrm{mM})$ were employed as hydroxyl radical $\left(\mathrm{OH}^{\bullet}\right)$, superoxide radical $\left(\mathrm{O}_{2}{ }^{\cdot-}\right)$, and hole $\left(\mathrm{h}^{+}\right)$scavengers, respectively. The photocatalytic activity of $1.0 \mathrm{~mol} \% \mathrm{Cu}$-doped $\mathrm{InVO}_{4}$ significantly decreased when BQ was added, implying that photogenerated superoxide anion radicals were the predominant active species for $\mathrm{MB}$ photodegradation, rather than photogenerated hydroxyl radicals or photogenerated holes (Fig. 9).

\section{Conclusions}

Pure $\mathrm{InVO}_{4}$ and 0.5-5.0 mol\% Cu-doped $\mathrm{InVO}_{4}$ catalysts were successfully synthesized via a hydrothermal method. The photocatalytic activities of all the samples were evaluated by monitoring the photocatalytic degradation of $\mathrm{MB}$ under visible light irradiation. The $1.0 \mathrm{~mol} \% \mathrm{Cu}$-doped $\mathrm{InVO}_{4}$ photocatalyst exhibited much higher photocatalytic activity than the other samples. The enhanced photocatalytic activities of $\mathrm{Cu}$-doped InVO $_{4}$ could be ascribed to the efficient separation and migration of photogenerated charge carriers, as well as the decreased recombination probability of electron-hole pairs derived from the $\mathrm{Cu}$ doping effect. These experiments demonstrate that $\mathrm{Cu}$ doped $\mathrm{InVO}_{4}$ photocatalysts can be readily produced with the requisite properties for use in water treatment applications, where their photocatalytic properties can be employed in the degradation of emerging environmental pollutants.

\section{Acknowledgements}

The authors gratefully acknowledge the financial support from the Thailand Research Fund (TRF) and the Higher Education Commission (CHE), as well as the Materials Science Research Center, Department of Physics and Materials Science, Faculty of Science, Chiang Mai University.

\section{References}

1 A. Sivakumar, B. Murugesan, A. Loganathan and P. Sivakumar, J. Taiwan Inst. Chem. Eng., 2014, 45, 23002306.

2 O. Carp, C. L. Huisman and A. Reller, Prog. Solid State Chem., 2004, 32, 42-90.

3 Y. Chen, R. Huang, D. Chen, Y. Wang, W. Liu, X. Li and Z. Li, ACS Appl. Mater. Interfaces, 2012, 4, 2273-2279.

4 G. Li, B. Jiang, X. Li, Z. Lian, S. Xiao, J. Zhu, D. Zhang and H. Li, ACS Appl. Mater. Interfaces, 2013, 5, 7190-7197.

5 E. Forgacsa, T. Cserhátia and G. Oros, Environ. Int., 2004, 30, 953-971.

6 S. Bae, S. Kim, S. Lee and W. Choi, Catal. Today, 2014, 224, 21-28.

7 H. Zhang, R. Zong, J. Zhao and Y. Zhu, Environ. Sci. Technol., 2008, 42, 3803-3807.

8 A. D. Paola, E. García-López, G. Marcì and L. Palmisano, J. Hazard. Mater., 2012, 211-212, 3-29.

9 L. Song, S. Liu, Q. Lu and G. Zhao, Appl. Surf. Sci., 2012, 258, 3789-3794.

10 T. H. Noh, D. W. Kim, S. W. Seo, I. S. Cho, D. H. Kim, H. S. Han and K. S. Hong, Mater. Lett., 2012, 72, 98-100.

11 F. Guo, W. Shi, X. Lin, X. Yan, Y. Guo and G. Che, Sep. Purif. Technol., 2015, 141, 246-255.

12 X. Lin, D. Xu, J. Zheng, M. Song, G. Che and Y. Wang, J. Alloys Compd., 2016, 688, 891-898.

13 J. Shen, X. Li, W. Huang, N. Li and M. Ye, Mater. Res. Bull., 2013, 48, 3112-3116.

14 Y. Wang, H. Dai, J. Deng, Y. Liu, Z. Zhao, X. Li and H. Arandiyan, Chem. Eng. J., 2013, 226, 87-94.

15 X. Lin, X. Guo, W. Shi, L. Zhao, Y. Yan and Q. Wang, J. Alloys Compd., 2015, 635, 256-264.

16 M. Yan, Y. Yan, C. Wang, W. Lu and W. Shi, Mater. Lett., 2014, 121, 215-218.

17 K. Vignesh, R. Hariharan, M. Rajarajan and A. Suganthi, Mater. Sci. Semicond. Process., 2013, 16, 1521-1530.

$18 \mathrm{~J}$. Chaisorn, K. Wetchakun, S. Phanichphant and N. Wetchakun, Mater. Lett., 2015, 160, 75-80.

19 J. Shen, H. Yang, Y. Feng, Q. Cai and Q. Shen, Solid State Sci., 2014, 32, 8-12.

20 X. Lin, D. Xu, Z. Lin, S. Jiang and L. Chang, RSC Adv., 2015, 5, 84372-84380.

21 X. Lin, X. Guo, W. Shi, F. Guo, G. Che, H. Zhai, Y. Yan and Q. Wang, Catal. Commun., 2015, 71, 21-27.

22 J. P. Allen, N. M. Galea, G. W. Watson, R. G. Palgrave, J. M. Kahk, D. J. Payne, M. D. M. Robinson, G. Field, A. Regoutz and R. G. Egdell, J. Phys. Chem. C, 2014, 118, 25330-25339. 
23 W.-J. Yin, S.-H. Wei, M. M. Al-Jassim, J. Turner and Y. Yan, Phys. Rev. B: Condens. Matter Mater. Phys., 2011, 83, 155102-155111.

24 S. Mahapatra, S. K. Nayak, G. Madras and T. N. G. Row, Ind. Eng. Chem. Res., 2008, 47, 6509-6516.

25 A. D. Paola, E. García-López, S. Ikeda, G. Marci, B. Ohtani and L. Palmisano, Catal. Today, 2002, 75, 87-93.

26 B. Hu, F. Cai, T. Chen, M. Fan, C. Song, X. Yan and W. Shi, ACS Appl. Mater. Interfaces, 2015, 7, 18247-18256.

27 Y. Li, M. Cao and L. Feng, Langmuir, 2009, 25, 1705-1712.

28 W. Shi, F. Guo, J. Chen, G. Che and X. Lin, J. Alloys Compd., 2014, 612, 143-148.

29 X. Lin, Y. Wang, J. Zheng, C. Liu, Y. Yang and G. Che, Dalton Trans., 2015, 44, 19185-19193.

30 Y. Yan, F. Cai, Y. Song and W. Shi, Chem. Eng. J., 2003, 233, 17.

31 Z. Ai, L. Zhang and S. Lee, J. Phys. Chem. C, 2010, 114, 1859418600.

32 J.-M. Yao, C.-K. Lee, S.-J. Yang and C.-S. Hwang, J. Alloys Compd., 2009, 481, 740-745.

33 Y. Yan, X. Liu, W. Fan, P. Lv and W. Shi, Chem. Eng. J., 2012, 200-202, 310-316.

34 C. S. Enache, D. Lloyd, M. R. Damen and J. Schoonman, J. Phys. Chem. C, 2009, 113, 19351-19360.

35 S. I. Naya, M. Tanaka, K. Kimura and H. Tada, Langmuir, 2011, 27, 10334-10339.

36 M. Khairy and W. Zakaria, Egypt. J. Pet., 2014, 23, 419-426.

37 B. Liu, L.-M. Liu, X.-F. Lang, H.-Y. Wang, X. W. Lou and E. S. Aydil, Energy Environ. Sci., 2014, 7, 2592-2597.

38 F. Chen, P. Fang, Z. Liu, Y. Gao, Y. Liu, Y. Dai, H. Luo and J. Feng, J. Mater. Sci., 2013, 48, 5171-5179.

39 J. D. Eversole and H. P. Broida, Phys. Rev. B: Solid State, 1977, 15, 1644-1655.

40 J. Ye, Z. Zou, M. Oshikiri, A. Matsushita, M. Shimoda, M. Imai and T. Shishido, Chem. Phys. Lett., 2002, 356, 221226.

41 H. Yan, X. Wang, M. Yao and X. Yao, Prog. Nat. Sci., 2013, 23, 402-407.

42 G. Yan, H. Shi, H. Tan, W. Zhu, Y. Wang, H. Zang and Y. Li, Dalton Trans., 2016, 45, 13944-13950.
43 N. Cimino, F. Artuso, F. Decker, B. Orel, A. ŠurcaVuk and R. Zanoni, Solid State Ionics, 2003, 165, 89-96.

44 A. Abrutis, L. Parafianovic, V. Kazlauskiene, V. Kubilius, G. Sauthier and A. Figueras, Surf. Coat. Technol., 2010, 204, 3864-3870.

45 S.-W. Cao, J. Fang, M. M. Shahjamali, F. Y. C. Boey, J. Barber, S. C. J. Loo and C. Xue, RSC Adv., 2012, 2, 5513-5515.

46 G. Xiao, X. Wang, D. Li and X. Fu, J. Photochem. Photobiol., A, 2008, 193, 213-221.

47 Y. Wang, H. Dai, J. Deng, Y. Liu, Z. Zhao, X. Li and H. Arandiyan, Chem. Eng. J., 2013, 26, 7-94.

48 Z. Jiang, Y. Liu, T. Jing, B. Huang, X. Zhang, X. Qin, Y. Dai and M.-H. Whangbo, J. Phys. Chem. C, 2016, 120, 2058-2063.

49 K. Song, J. Zhou, J. Bao and Y. Feng, J. Am. Ceram. Soc., 2008, 91, 1369-1371.

50 H. W. P. Carvalho, M. V. J. Rocha, P. Hammer and T. C. Ramalho, J. Mater. Sci., 2013, 48, 3904-3912.

51 J. Yu, Y. Hai and M. Jaroniec, J. Colloid Interface Sci., 2011, 357, 223-228.

52 Z. Luo and Q. H. Gao, J. Photochem. Photobiol., A, 1992, 96, 367-375.

53 A. Murashkina, P. D. Murzin, A. V. Rudakova, V. K. Ryabchuk, A. V. Emeline and D. W. Bahnemann, J. Phys. Chem. C, 2015, 119, 24695-24703.

54 S. M. Gupta and M. Tripathi, Chin. Sci. Bull., 2011, 56(16), 1639-1657.

55 O. Ola and M. M. Maroto-Valer, J. Photochem. Photobiol., C, 2015, 24, 16-42.

56 C.-R. Lee, H. S. Kim, I.-H. Jang, J.-H. Im and N.-G. Park, ACS Appl. Mater. Interfaces, 2011, 3, 1953-1957.

57 S. Khezrianjoo and H. D. Revanasiddappa, Chem. Sci. J., 2012, CSJ-85, 1-8.

58 H. Q. Jiang, H. Endo, H. Natori, M. Nagai and K. Kobayashi, Mater. Res. Bull., 2009, 44, 700-706.

59 F. Guo, W. Shi, X. Lin, X. Yan, Y. Guo and G. Che, Sep. Purif. Technol., 2015, 141, 246-255.

60 G. Magesh, B. Viswanathan, R. P. Viswanath and T. K. Varadarajan, Indian J. Chem., Sect. A: Inorg., Bio-inorg., Phys., Theor. Anal. Chem., 2009, 48, 480-488.

61 Y. Nosaka and A. Y. Nosaka, J. Phys. Chem. Lett., 2016, 7, 431434. 